\title{
Fundamentos del Principio de Distinción en el Derecho Internacional Humanitario ${ }^{1}$
}

\author{
Fundaments of the Principle of Distinction in International Humanitarian Law
}

\section{Ruggero Cozzi Elzo}

ruggero.cozzi.elzo@gmail.com

Abogado. Licenciado en Derecho, Pontificia Universidad Católica de Chile. Magister en Derecho (LL.M.) en Crimen y Justicia Internacional, Universidad de Turín. Profesor de Derechos Humanos en la Universidad de Los Andes, Santiago de Chile.

Resumen: El principio de distinción obliga a los Estados a distinguir entre civiles y combatientes en el contexto de los conflictos armados. Según la Corte Internacional de Justicia, se trata de uno de los pilares del derecho internacional humanitario. Al respecto, se revisan los fundamentos de este principio general del derecho internacional. Desde una perspectiva histórica, el principio de distinción pasa por distintas etapas, hasta llegar a su reconocimiento positivo en los tratados internacionales, observando cambio y continuidad en algunas de sus notas esenciales. Desde una mirada política, el principio refleja un delicado balance de intereses estatales, entre necesidad militar y humanidad. Finalmente, este principio se justifica en consideraciones éticas que, si bien generan discusión en la doctrina en cuanto sus implicancias, denotan el fuerte componente moral de esta obligación internacional de los Estados.

Palabras clave: principio de distinción - principio de discriminación - derecho internacional humanitario combatientes - civiles

\begin{abstract}
Under the principle of distinction States are obliged to distinguish between civilians and combatants in the context of armed conflict. According to the International Court of Justice, this is one of the cardinal pillars of international bumanitarian law. The author reviews the foundations of this general principle of international law from a bistorical, political and etbical perspective. From a bistorical perspective, the principle of distinction goes through different stages, until it reaches its positive recognition in international treaties, observing change and continuity in some of its essential notes. From a political perspective, the principle of distinction reflects a delicate balance of state interests, between military necessity and bumanity. Finally, the principle of distinction is justified due to etbical considerations that, while generating discussion in the doctrine as to its implications, denote the strong moral component of this international obligation of States.
\end{abstract}

Keywords: principle of distinction - principle of discrimination - international humanitarian law combatants - civilians

1 Artículo enviado el 30.10.2019 y aceptado el 21.01.2020.

Número de página no utilizable para citar 


\section{Introducción}

Los principios generales del derecho reconocidos por las naciones civilizadas son una fuente formal del derecho internacional. Los principios se aplican no de modo auxiliar (como la jurisprudencia y doctrina) sino de modo directo (al igual que los tratados y costumbre). ${ }^{2}$ Además, en su sentido funcional los principios jurídicos informan la creación del derecho consuetudinario y convencional, permiten interpretar las normas vigentes, integrar las lagunas, superar antinomias, y eventualmente hacer correcciones lege ferenda. En suma, contribuyen a forjar la coherencia del orden jurídico normativo y sirven para llenar las lagunas del derecho (Moderne, 2005: 36).

En su Opinión consultiva sobre la Legalidad de la amenaza o el empleo de armas nucleares la Corte Internacional de Justicia (CIJ) ha declarado que los dos 'pilares cardinales' del derecho internacional humanitario $(\mathrm{DIH})$ son la prohibición de causar sufrimientos innecesarios y males superfluos, y también, el principio de distinción. En lo que interesa a este breve trabajo, y en palabras de la CIJ, el principio de distinción "se dirige a la protección de la población civil y los objetos civiles, estableciendo la distinción entre combatientes y no combatientes; los Estados nunca pueden hacer de los civiles el objetivo de un ataque y consecuentemente nunca deben emplear armamentos que sean incapaces de distinguir entre civiles y blancos militares" (CIJ 1996: 257).

El principio de distinción está reconocido positivamente en el artículo 48 del Protocolo Adicional I de 1977 aplicable a los conflictos armados internacionales. ${ }^{3}$ Como dice el encabezado de aquel precepto, se trata de una "Norma Fundamental": "A fin de garantizar el respeto y la protección de la población civil y de los bienes de carácter civil, las Partes en conflicto harán distinción en todo momento entre la población civil y combatientes, y entre bienes de carácter civil y objetivos militares y, en consecuencia, dirigirán sus operaciones únicamente contra objetivos militares" (cursiva es nuestra).

La distinción entre civiles y combatientes se entiende a la luz del artículo $1^{\circ}$ del Reglamento de La Haya IV. ${ }^{4}$ Este último precepto establece las condiciones para ser considerado como combatiente ante el derecho internacional. En efecto, son cuatro las condiciones impuestas por el DIH para constituir un ejército regular: i) tener a la cabeza una persona responsable por sus subalternos; ii) tener una señal como distintivo fijo y reconocible a distancia; iii) llevar las armas

Estatuto de la Corte Internacional de Justicia, artículo 38.1(c).

3 Protocolo I adicional a los Convenios de Ginebra de 1949 relativo a la protección de las víctimas de los conflictos armados internacionales, Ginebra, 8 de junio de 1977 (PA I).

4 Convención relativa a las leyes y costumbres de la guerra terrestre y su Anexo, La Haya, 18 de octubre de 1907 (RH IV).

Número de página no utilizable para citar 
ostensiblemente; iv) sujetarse en sus operaciones a las leyes y costumbres de la guerra ${ }^{5}$. Entonces, quien desee participar legítimamente en las hostilidades, y para adquirir el status de combatiente, debe enlistarse en un ejército que cumpla con estas cuatro condiciones. De lo contrario, esa persona mantiene su estatus de civil.

La regla general puede resumirse en la siguiente fórmula: quien no es un combatiente, es un civil. Y las personas en una y otra categoría están sometidas a distintos derechos y deberes.

En primer lugar, los combatientes tienen derecho a participar directamente en las hostilidades ${ }^{6}$. Es lo que se conoce como el 'privilegio' del combatiente: esto es, inmunidad de persecución penal por actos militares legítimos (p.ej. ataques, lesiones, incendio, etc., en contra de personas o bienes autorizados por el DIH). En el contexto del conflicto armado, los combatientes están autorizados a matar, herir o capturar a los combatientes enemigos -y sólo a ellos- así como a destruir la propiedad ajena, militar o civil, bajo ciertas condiciones. Los actos militares legítimos quedan cubiertos dentro del 'privilegio' del combatiente. El límite está enmarcado por el propio DIH. Lo que desborda dichos límites es una infracción internacional del Estado y en ocasiones un crimen de guerra.

En segundo lugar, los combatientes tienen derecho al estatus de prisionero de guerra $(\operatorname{PdG})^{7}$. Importante es aclarar que los PdG no son "criminales" aprehendidos por cometer algún ilícito; los campamentos de PdG no son "cárceles". Muy por el contrario, el PdG es un combatiente que cae en poder del enemigo, pero que goza de un estatuto jurídico que lo protege enormemente $^{8}$. El Estado detentor tiene derecho a retener a los PdG, pero debe protegerlos. No hacerlo es una grave infracción del DIH y a veces incluso un crimen de guerra. La lógica de la institución de los PdG es inhabilitar combatientes del Estado enemigo, para obtener una ventaja militar. Guardando las proporciones, es como tomar una "ficha" del tablero de ajedrez: se retiene mientras dure la partida, pero se devuelve una vez que está claro quién es el vencedor; y debe devolverse íntegramente. Igualmente, los PdG deben ser repatriados una vez que culmina el conflicto armado.

En tercer lugar, los combatientes tienen la obligación de respetar las normas de DIH. Por regla general, los combatientes forman parte de un órgano del Estado, y como tal, están obligados por el derecho internacional. Las infracciones del DIH, cometidas por combatientes, frecuentemente gatillan la responsabilidad internacional del Estado. Asimismo, los

RH IV, art. $1^{\circ}$.

RH IV, art. $1^{\circ}$; PA I, art. 43(2).

RH IV, art. 3; PA I de 1977, artículo 44(1).

P.ej. tienen derecho a condiciones mínimas de higiene y atención médica, comida y vestimenta, libertad religiosa, protección frente a los ataques, derecho a mantener correspondencia con familiares, derecho a quejas por malas condiciones de cautividad, eligen representantes dentro del campo de prisioneros, e incluso, aunque a muchos les sorprenda, tienen derecho a fugarse del campo de prisioneros, entre otros.

Número de página no utilizable para citar 
combatientes son responsables personalmente por los crímenes de guerra que puedan cometer. Los crímenes de guerra son infracciones graves al DIH. Estos delitos pueden tener una sanción doméstica, por ejemplo, como sucede con aquellos ilícitos penados por el Código Militar, o cuando existe una persecución doméstica de crímenes de guerra internacionales ${ }^{9}$. También podrían ser sancionados por el Estado adversario ${ }^{10}$. Y excepcionalmente, la conducta podría traer aparejada una pena de índole internacional, como ocurre con los crímenes de guerra sancionados por el Estatuto de Roma ${ }^{11}$.

El estatuto de la población civil es diametralmente distinto. Los 'civiles' son una categoría definida por defecto (default rule). La regla es sencilla: todo aquel que no es un combatiente, es un civil ${ }^{12}$. Y la población civil tiene un gran derecho: "La población civil y las personas civiles gozarán de protección general contra los peligros procedentes de operaciones militares"13. Ello supone que "no serán objeto de ataque", ni la población civil como tal, ni las personas civiles individualmente consideradas ${ }^{14}$. Prohibiéndose expresamente los 'ataques indiscriminados', es decir, aquellos que no distinguen entre los objetivos militares y la población civil ${ }^{15}$.

Lógicamente, de aquella protección general se desprenden varios corolarios: la prohibición de los llamados "escudos humanos"16; prohibición del terrorismo, pillaje y represalias contra la población civil $^{17}$; prohibición de la toma de rehenes ${ }^{18}$; prohibición de métodos de guerra inhumanos, como hacer padecer hambre a las personas civiles ${ }^{19}$; por mencionar algunos. También se han establecido ciertas categorías de civiles especialmente protegidos por el DIH: las mujeres y los niños ${ }^{20}$. Asimismo, los Estados han asumido la obligación de facilitar y permitir el envío de ayuda humanitaria a la población civil, incluso aquella del Estado $\operatorname{adversario}^{21}$.

\footnotetext{
En Chile, en virtud de la Ley 20.357 que Tipifica Crímenes de Lesa Humanidad y Genocidio y Crímenes y Delitos de Guerra, arts. 16 a 24.

10 Convenio III de Ginebra relativo al trato debido a los prisioneros de guerra, Ginebra, 12 de agosto de 1949 (CG III), art. 99

11 Estatuto de Roma de la Corte Penal Internacional, art. 8. Esto, únicamente, en coherencia con el principio de complementariedad, Estatuto de Roma, arts. 1 y 17.

12 PA I, art. 50.

13 PA I, art. 51(1).

14 PA I, art. 51(2).

5 PA I, art. 51(4)-(5).

16 Convenio IV de Ginebra relativo a la protección debida a las personas civiles en tiempo de guerra, Ginebra, 12 de agosto de 1949 (CG IV), art. 28.

17 CG IV, art. 33.

18 CG IV, art. 34

19 Estatuto de Roma de la Corte Penal Internacional, art. 8(2).

20 CG IV, art. 24 y 27.

21 PA I, art. 70(2).
}

Número de página no utilizable para citar 
Aunque repasar todas las prohibiciones y obligaciones de los Estados establecidas para la protección general de la población civil en los conflictos armados, escapa el objetivo de este ensayo, es importante insistir en que el principio de distinción entre combatientes y civiles está detrás de todas esas reglas.

Sin perjuicio de todo lo dicho, la población civil tiene igualmente un gran deber, cual es, no participar de las hostilidades. Esta prohibición dirigida a la población civil es correlativa a su protección. Por lo mismo, el DIH reconoce que, incumplida esta obligación, los combatientes quedan temporalmente autorizados a dirigir sus ataques contra aquellos civiles que tomen las armas o colaboren con el esfuerzo bélico del Estado adversario. Temporalmente, entonces, los civiles participando directamente en las hostilidades quedan desprotegidos. Así, el artículo 51(3) del PA I de 1977 establece: "Las personas civiles gozarán de la protección que confiere esta Sección, salvo si participan directamente en las hostilidades y mientras dure tal participación" (cursiva es nuestra).

Además de la temporal desprotección en que quedan los civiles participando directamente de las hostilidades, éstos, a su vez, quedan expuestos a ser sancionados por los delitos que cometan, frente al derecho doméstico e internacional. Es por ello que se les denomina 'combatientes irregulares' o 'combatientes ilegales' (unlanful combatants) (Dinstein, 2003).

En suma, el principio de distinción busca lograr la máxima protección posible de la población civil frente a las hostilidades propias de un conflicto armado. $\mathrm{Y}$ al respecto, surge una interrogante elemental: ¿cuál es el fundamento de este principio y obligación internacional? Intentaremos responder a esta pregunta en las próximas líneas, desde una perspectiva histórica, política y ética.

\section{Fundamentos de la distinción entre combatientes y civiles en el contexto de los conflictos armados}

\subsection{Perspectiva histórica}

Podemos encontrar las raíces históricas del ius in bello en las civilizaciones babilónica (código de Hammurabi), india (ley de Manu), griega y romana (ius fetiale), entre otras, con un posterior desarrollo medieval en la tradición cristiana (códigos de caballería), oriental (bushi-do) e islámica. Las bases doctrinales del DIH moderno, sin embargo, se deben principalmente a la reflexión filosófica occidental de la escuela iusnaturalista -Francisco de Vitoria, Hugo Grocio-

Número de página no utilizable para citar

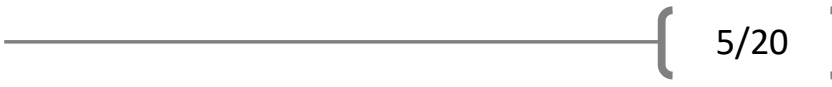


y contractualista - Thomas Hobbes, J.J. Rousseau- que más adelante se plasman en los tratados europeos de fines del siglo XIX (O'Connell, 2013: 15-20).

En lo que concierne al principio de distinción entre combatientes y civiles, Marco Tulio Cicerón, en su obra De Officiis, señala que de acuerdo al ius fetiale romano ${ }^{22}$ ninguna persona podía lícitamente participar de la guerra con el enemigo público sin antes enrolarse en el ejército y prestar el juramento militar (Draper, 1972: 140). Así, Álvaro D'Ors explica que el ejército, aunque compuesto de ciudadanos, está fuera del pueblo (Populus) y no pertenece propiamente a la república: "Precisamente porque debe defender a la república, no puede pertenecer a ella, pues el defensor no puede confundirse con el defendido: el Ejército es el defensor y el pueblo -la república- es el defendido". Ello explicaría el régimen excepcional de las fuerzas armadas (imperium militae), en contraposición al ordenamiento jurídico que aplicaba a los civiles (imperium domi) (D'Ors, 2003: 199-120). Esta noción de una clase social excepcionalmente autorizada a participar en la guerra, con derecho a realizar actos de combate, es transversal a todos los períodos históricos y civilizaciones.

Sin embargo, hay aspectos que han cambiado a lo largo de los siglos. En general el DIH antiguo no concedía protección a los enemigos extranjeros, quienes se exponían a la muerte o esclavitud. Aun así, ya en el mundo antiguo los soldados tenían prohibido atacar a la población civil a menos que los ciudadanos ofrecieran resistencia a la invasión de su ciudad. En la tradición islámica, por ejemplo, durante las guerras islámicas, una de las órdenes del primer califa Abu Bakr (circa 632) fue que "la sangre de mujeres, niños y ancianos no debe manchar tu victoria". Y aunque sobran ejemplos de brutales saqueos e incendios de ciudades enteras en este período histórico, la obligación de distinguir entre combatientes y civiles existe desde tiempos remotos (O'Connell, 2013: 17).

Con todo, el principal desarrollo del principio de distinción vendrá en la Edad Media, de la mano de la filosofía escolástica.

Como es sabido, la doctrina católica de la guerra justa -que se remonta a San Agustín de Hipona, pero que será sistematizada con Santo Tomás de Aquino- establecía tres condiciones de justicia para declarar la guerra: i) primero, requiere la autoridad del príncipe bajo cuyo mandato se hace la guerra, pues a él le incumbe defender el bien público contra los perturbadores internos y contra los enemigos externos; ii) segundo, una causa justa, es decir, que quienes son atacados lo merezcan por alguna causa; iii) tercera, que sea recta la intensión de los contendientes, es decir, una intención encaminada a promover el bien o a evitar el mal (véase Suma Teológica II-IIae, c. 40).

22 El ius fetiale era una suerte de derecho divino ejercido por los fetiales, especie de sacerdotes entre los cuales uno de ellos, el pater patratus, tenía la facultad de llevar adelante los ritos y ceremoniales para declarar la guerra (indictio belli) a fin de ser asistidos por los dioses (Buono-Cuore 2003, 23-34).

Número de página no utilizable para citar 
Estas limitaciones propias del ius ad bellum, lógicamente, tuvieron repercusiones en el modo de entender el ius in bello medieval, que en los siglos XV y XVI alcanza un alto grado de tecnicismo y sofisticación con los códigos de caballería. En primer lugar, dado que sólo puede ser declarada lícitamente por la autoridad del príncipe, se rechaza la guerra privada y la utilización de mercenarios, restringiendo celosamente quiénes tienen el derecho -privilegio, para estos efectos- de participar en la guerra pública. En segundo lugar, y como consecuencia de lo anterior, surgirá una casta exclusiva de caballeros y profesionales de las armas, guiados por el honor y la recompensa, con un estatuto jurídico personal. Infringir el código de caballería significaba perder el honor, o el premio del rey, o ambos -además de una eventual condena en el infierno- (Draper, 1972: 136-137). La doctrina de la guerra justa, en suma, no sólo establecía condiciones exigentes para declarar la guerra, sino que, también, reducía al mínimo la clase de personas autorizadas para participar directamente de las hostilidades. Sin embargo, el trato a los combatientes enemigos que peleaban una guerra sin justa causa -v.gr. infieles, mercenarios- era inconmovible: se les consideraba culpables y existía derecho a castigarlos, incluso con la muerte. Así aparece, por ejemplo, en las Relecciones sobre los indios y el derecho de guerra de Francisco Vitoria (párr. 46-48) ${ }^{23}$.

Esto es bien diferente del DIH moderno, en que los prisioneros de guerra no son tratados como "culpables" - a menos que exista condena por algún delito militar o crimen de guerrasino que gozan de diversos derechos y protecciones (Krahenmann, 2013: 359-412).

Con la reforma protestante y el surgimiento de principados rebeldes, especialmente en las guerras religiosas, vuelven a la escena bélica los ejércitos privados compuestos por mercenarios y movidos por el afán lucrativo. Éstos no tienen consideraciones en el honor ni hacen distinción entre combatientes y población civil (O'Connell, 2013: 19). La crueldad y desastre de las guerras religiosas, precisamente, motivó las reflexiones de Hugo Grocio en su obra De iure belli ac pacis de 1625. Quizás por eso, luego de la paz de Westfalia en 1648, una de las características del incipiente Estado moderno será la posesión de un ejército público, financiado con recursos fiscales y al servicio del soberano. Comienza con ello el período de la raison d'état y la influencia de las ideas ilustradas. No obstante, la introducción de ejércitos permanentes entre los siglos XVII y XVIII solamente extendió el número, pero no la clase, de personas habilitadas para participar en las hostilidades. Aunque la noción del honor militar desaparece, los nuevos Estados entenderán que es de su propio interés en las relaciones internacionales el restringir la participación en la guerra sólo a una clase 'privilegiada' de personas, profesionalizadas y disciplinadas (Draper, 1972: 138-139).

23 Aunque Vitoria propone como regla general castigar a los enemigos según la gravedad de la injuria cometida, en el párr. 48 se nota el rigor de la tradición clásica: a veces es lícito y conveniente dar muerte a todos los enemigos para conseguir la paz y la seguridad, p.ej., dice, en la guerra contra los infieles.

Número de página no utilizable para citar 
En el período de la Ilustración el cambio más radical viene con la propuesta de una separación estricta entre ius ad bellum e ius in bello. Desde una mirada iluminista, las razones de un Estado para hacer la guerra a otro Estado no debieran incidir en la protección de los combatientes, meros súbditos obligados a tomar las armas. En palabras de J.J. Rousseau: "La guerra no es una relación de hombre a hombre, sino de Estado a Estado, en la cual los individuos son enemigos accidentalmente, no como hombres ni como ciudadanos, sino como soldados; no como miembros de la patria, sino como sus defensores [...] Teniendo la guerra como fin de destrucción del Estado enemigo, hay derecho de matar a los defensores mientras están con las armas en la mano, pero tan pronto como las entregan y se rinden, dejan de ser enemigos o instrumentos del enemigo, recobran su condición de simples hombres y el derecho a la vida [...]" (El Contrato Social, Libro I, Cap. IV). Así, deja de ser relevante el casus bellus y adquiere mayor importancia los derechos mismos de la persona. Por ello la tendencia será a proteger a los combatientes por motivos humanitarios, con independencia de la justicia o injusticia de las causas de la guerra. La visión rousseauniana será una de las bases modernas del principio de distinción, entendiendo que para alcanzar la victoria militar basta con inhabilitar al enemigo sin que sea necesario aniquilarlo (O'Connell, 2013: 19-20). Esta es la raíz, por ejemplo, del estatus legal de prisionero de guerra: una vez concluido el conflicto, los prisioneros de guerra deben ser restituidos -en condiciones íntegras- al Estado adversario. Ahora bien, sin perjuicio de su influencia teórica, la consagración jurídica de estas ideas ilustradas tardaría todavía varias décadas.

Siglo trascendental, el XIX puede dividirse en dos momentos que influirán decisivamente en la evolución del principio de distinción. En la primera mitad de siglo, durante las guerras napoleónicas entre 1803 y 1815, se planteó el problema de los combatientes irregulares. Aunque se trata de un viejo tema del ius in bello, pues siempre había existido una noción de combatientes injustos o sin derecho - p.ej. infieles, mercenarios- esta vez el asunto tiene un nuevo trasfondo y motivación: el nacionalismo. La idea de 'guerras patriotas' con hombres peleando en grupos desorganizados contra las fuerzas militares invasoras, ya fuesen los restos de un ejército nacional o como civiles causando estragos en las líneas enemigas, fue una experiencia compartida por varios gobiernos -España, Rusia, etc.-. Lo que, sumado al romanticismo imperante, llevó a plantear la posibilidad de reconocer jurídicamente aquellas "bandas irregulares" de hombres peleando. Sin embargo, el sentimiento nacionalista no logró modificar sustancialmente la tradición jurídica imperante. Las guerrillas -como las denominaron los franceses al invadir España- son anatema para la clase militar profesional; peor aún, estratégicamente son muy peligrosas. No pelean bajo la disciplina militar del Estado; frecuentemente no usan uniforme; se despreocupan de la seguridad de sus prisioneros; y en muchos casos, sus ataques difícilmente pueden distinguirse del pillaje y bandidaje. Un tratadista de la época afirmaba que el consenso internacional post-1830 era darle reconocimiento a los grupos armados irregulares solamente en la medida que fuesen autorizados, expresa o 
tácitamente, por un Estado; por regla general, los grupos irregulares estaban expuestos a ser tratados como "bandidos sin derechos", excluidos de la protección de los usos y costumbres de la guerra entre naciones civilizadas (Draper, 1972: 139-140) ${ }^{24}$.

La segunda mitad del siglo XIX ofrecerá, a su vez, dos novedades: primero, el movimiento humanitarista iniciado por Henry Dunant; y segundo, la tendencia a la codificación, que extendió su influencia al ámbito del DIH. En este período, el paradigma continúa siendo la guerra tradicional entre Estados y las batallas siguen ocurriendo mayoritariamente entre ejércitos en terreno abierto. Por eso, la evolución del DIH en estos años se sigue concentrando en los derechos y deberes de los combatientes (Draper, 1972: 141). Fue la desatención de los aproximadamente 40.000 soldados heridos en la batalla de Solferino en 1859 lo que gatilló la reflexión humanitaria y posterior reforma de los usos y costumbres de la guerra. En su Recuerdo de Solferino de 1862, Henry Dunant propuso crear sociedades de socorro y establecer principios internacionales para el auxilio de los militares heridos en el campo de batalla, sin distinción del bando a que pertenecen. Ello será recogido en el Convenio de Ginebra para el mejoramiento de la suerte de los militares heridos en los ejércitos en campaña de 1864 (Kleffner, 2013: 321-322). Por fin, las ideas rousseaunianas tenían algún grado de expresión jurídica.

El positivismo jurídico, por su lado, imprimió su sello a través de una serie sucesiva de conferencias, declaraciones y tratados internacionales que irán escriturando el ius in bello vigente en la segunda mitad del siglo XIX. Particular influencia tuvo el esfuerzo de Francis Lieber de redactar un "código" aplicable en la guerra civil de EE.UU., y que adquiere validez jurídica al ser promulgado como una instrucción a los ejércitos federales, conocida popularmente como Código Lieber de $1863^{25}$. Por cierto, el principio de distinción entre combatientes y civiles se manifiesta transversalmente en varios pasajes de este Código, que dispone lo siguiente: la necesidad militar admite la destrucción directa de la vida e integridad física de los enemigos armados, y de otras personas cuya destrucción es incidentalmente inevitable en los conflictos armados (art. 15); debe distinguirse entre el individuo privado que pertenece a un país hostil y el país hostil en sí mismo, con sus hombres de armas, de modo que, por principio, la vida, propiedad y honor de los civiles desarmados deben quedar eximidas de los efectos de las hostilidades en la medida que lo permitan las exigencias de la guerra (art. 22); se prohíbe asesinar, esclavizar o deportar a los ciudadanos privados (art. 23); la protección de los ciudadanos inofensivos es la regla general (art. 25); entre otras disposiciones.

24 Citando a H. Wheaton, Elements of International Law, IV Parte, 1836, párr. 356.

25 Adjutant General's Office, General Orders No. 100: Instructions for the government of armies of the united states in the field, Washington, 1863, disponible en Avalon Project: http://avalon.law.yale.edu/

Número de página no utilizable para citar 
Del lado europeo la codificación más importante será el reglamento anexo a la Convención relativa a las leyes y costumbres de la guerra terrestre de 1907, también conocido como Reglamento de La Haya IV $(\mathrm{RH} \text { IV })^{26}$. En lo concerniente al principio de distinción, el RH IV enumera los elementos que determinan la calidad de combatiente $\left(\right.$ art. $1^{\circ}$ ), regla básica que persiste con gran importancia hasta nuestros días. Además, introduce la excepcional figura del leveé en masse (art. 2); establece protecciones para los prisioneros de guerra (arts. 4-20); reitera la protección de enfermos y heridos (art. 21); y dispone que "los beligerantes no tienen un derecho ilimitado en cuanto a la elección de los medios de perjudicar al enemigo" (art. 22), estableciendo diferentes restricciones a la conducción de las hostilidades (arts. 23-28); entre otros.

Ya en el siglo XX, la revolución industrial trajo consigo -también- la industrialización y mecanización de la guerra, y ello se manifestó en toda su dramática extensión con las dos guerras mundiales. Éstas fueron batalladas, además, bajo el paradigma de la 'guerra total' que supone la solidaria participación del gobierno, ejército y población civil en los esfuerzos bélicos para lograr así una ventaja estratégica sobre el enemigo, haciendo de la guerra una empresa tanto política, militar y económica (Gray, 2007: 31-141) ${ }^{27}$. En ese contexto los Estados no escatimaron en dirigir sus ataques contra todo tipo de objetivos no militares, desde la destrucción de fábricas repletas hasta el bombardeo de ciudades completas, con las muertes que ello tristemente significa para los civiles.

El principal desafío para el principio de distinción, en este período, en efecto, fueron los bombardeos aéreos dirigidos directamente a la población civil. La primera guerra mundial entre 1914 y 1919, dejó en evidencia los vacíos existentes en el derecho de la guerra aérea y que hicieron de los ataques indiscriminados un problema incontrolable ${ }^{28}$. Como respuesta se formularon las Reglas de La Haya sobre la Guerra Aérea de 1923, pero éstas nunca fueron adoptadas formalmente por los Estados ya que ello significaba renunciar a una ventaja militar importante. Esta falta de regulación tuvo nefastas consecuencias en la segunda guerra mundial entre 1939 y 1945, bastando recordar los bombardeos de la Luftwaffe alemana -primero en Polonia, luego en el Reino Unido- así como la respuesta de "bombardeos de terror" de la Royal Air Force británica en

26 Convención relativa a las leyes y costumbres de la guerra terrestre y su Anexo, La Haya, 18 de octubre de 1907 (RH IV), disponible en: https://www.icrc.org/spa/resources/documents/misc/treaty-1907-regulations-laws-customs-war-on-land$5 \mathrm{tdm} 39 . \mathrm{htm}$

27 Por cierto, el cambio de paradigma venía ocurriendo progresivamente desde las guerras napoleónicas, teniendo como punto de quiebre la Revolución Francesa, que transformó radicalmente los motivos sociales y políticos de la violencia organizada; motivos que fueron profundizados en el siglo de las ideologías y de la técnica.

28 El problema era el siguiente: el art. 25 RH IV prohibía atacar o bombardear ciudades, aldeas o edificios 'que no estén defendidos'. Entendiendo que una ciudad indefensa eran aquellas que podían ser capturadas sin el uso de la fuerza, el bombardeo aéreo quedaba fuera del ámbito del art. 25 RH IV ya que las ciudades que eran atacadas desde el aire podían ser destruidas, pero no podían ser capturadas sin el uso de la fuerza.

Número de página no utilizable para citar 
las ciudades alemanas. Recién en 1977 fue posible establecer limitaciones internacionales a los bombardeos aéreos que fueran vinculantes para los Estados (O'Connell, 2013: 23-25) ${ }^{29}$.

Inmediatamente terminada la guerra, los Estados vencedores (EE.UU., Reino Unido, Francia y la U.R.S.S.) acordaron en la Carta de Londres de 1945 la creación del Tribunal Militar Internacional de Núremberg, con la finalidad de perseguir y juzgar a los mayores criminales de guerra del régimen $\mathrm{Nazi}^{30}$. Con los juicios todavía en curso, la Organización de Naciones Unidas (ONU) adoptó la Convención para la prevención y la sanción del delito de genocidio de 1948, y un año después se celebra la conferencia diplomática en que se adoptaron los cuatro Convenios de Ginebra de 1949 (CGs): el primero, sobre la protección de los combatientes fuera de combate en la guerra terrestre (CG I $)^{31}$; y el segundo, para la protección en la guerra marítima (CG II $)^{32}$; el tercero, dedicado a los prisioneros de guerra (CG III) ${ }^{33}$; y el cuarto, exclusivamente para la protección de la población civil (CG IV) ${ }^{34}$.

Con el advenimiento de la guerra fría entre 1951 y 1989 reaparecen en el escenario bélico las guerrillas irregulares. La principal novedad, esta vez, es que si las guerrillas del siglo XIX y los partisanos de la segunda guerra mundial combatían como respuesta a la ocupación e invasión extranjera - en el contexto de guerras internacionales- en la segunda mitad del siglo XX, en cambio, aparecen sinnúmero de conflictos armados internos o no internacionales (v.gr. guerras de descolonización en África y Asia, revoluciones de inspiración marxista en América Latina, etc.). Aquí se enfrenta el Estado contra sus propios ciudadanos -agrupados en organizaciones paramilitares, al margen de la ley doméstica- dentro del territorio donde el mismo Estado ejerce soberanía (Fleck, 2013: 581-608). Ya fuese como parte del proceso de descolonización o como pugna ideológica en su fase más extrema de violencia política, o por una mezcla de ambos, la nota característica será la multiplicación de 'conflictos asimétricos' que hacen difícil tácticamente para los Estados la implementación del DIH contra adversarios incapaces estructuralmente y/o indispuestos estratégicamente a respetar los límites del ius in bello (Münkler, 2003: 7-21). El cambio de escenario, y especialmente la vulnerabilidad de la población civil en este nuevo contexto, parecía requerir una actualización del DIH vigente que culminó con la adopción en 1977 de los dos Protocolos Adicionales a los Convenios de Ginebra de 1949.

29 Ver, Protocolo Adicional I de 1977, arts. 48-51, entre otros.

30 Estatuto del Tribunal Militar Internacional de Núremberg, anexo a la Carta de Londres, 8 de julio de 1945, disponible en Avalon Project: http:/ /avalon.law.yale.edu/imt/imtchart.asp

31 Convenio I de Ginebra para aliviar la suerte que corren los heridos y los enfermos de las fuerzas armadas en campaña, Ginebra, 12 de agosto de 1949 (CG I).

32 Convenio II de Ginebra para aliviar la suerte que corren los heridos, los enfermos y los náufragos de las fuerzas armadas en el mar, Ginebra, 12 de agosto de 1949 (CG II).

33 Convenio III de Ginebra relativo al trato debido a los prisioneros de guerra, Ginebra, 12 de agosto de 1949 (CG III).

34 Convenio IV de Ginebra relativo a la protección debida a las personas civiles en tiempo de guerra, Ginebra, 12 de agosto de 1949 (CG IV). 
El primero de éstos, el Protocolo Adicional I de 1977 (PA I), unificó el derecho de La Haya y Ginebra en un único tratado internacional, armonizando la regulación de la conducción de las hostilidades y la protección de personas y objetos en los conflictos armados internacionales ${ }^{35}$. El Protocolo Adicional II de 1977 (PA II), por su lado, fue el primer tratado en abordar

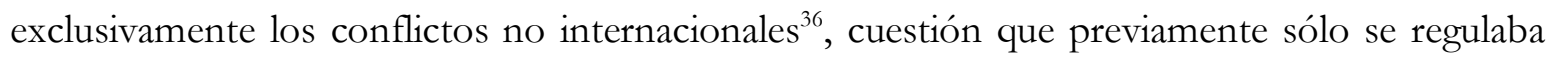
en el artículo 3 común a los cuatro CGs.

Nos detendremos en este punto de la evolución histórica del principio de distinción. De aquí en adelante bien puede decirse que entramos a un análisis del DIH vigente. Y por lo mismo, en el próximo acápite retomaremos el origen de la última gran reforma al DIH, desde la perspectiva del balance entre las consideraciones de necesidad militar y humanidad, probablemente la llave maestra para entender el principio de distinción entre combatientes y civiles.

\subsection{Necesidad militar y humanidad: un delicado balance}

Para comprender el DIH, no pueden desatenderse las razones políticas, estratégicas, operativas y tácticas de la conducta de los Estados en el campo de batalla. En lenguaje clausewitziano, la guerra es un instrumento de la política, y la toma de decisiones militares está guiada por la finalidad de prevalecer por la fuerza y derrotar la voluntad del adversario, para imponer las condiciones políticas que regirán en el período de paz; pero ello sin perder de vista la "gramática" propia de la guerra, que la hace inmanejable e impredecible en muchos sentidos (Gray, 2007: 15-27). Aquellas consideraciones, por cierto, influyen en la configuración del DIH positivo. Es por ello que, en un sentido funcional, el DIH puede definirse como un "equilibrio realista entre las consideraciones de necesidad militar y humanidad que ha sido reconocido por el derecho internacional" (Hayashi, 2016: 89) ${ }^{37}$.

Este 'delicado balance' entre necesidad militar y humanidad -como lo califica Michael N. Schmitt- se explica porque, precisamente, son los Estados quienes crean el derecho internacional con su consentimiento, tanto en los tratados escritos como en las prácticas que moldean la costumbre, y en consecuencia, son los intereses del Estado los que guían el desarrollo del DIH dentro de los márgenes y límites que los Estados estén dispuestos a imponerse

35 Protocolo I adicional a los Convenios de Ginebra de 1949 relativo a la protección de las víctimas de los conflictos armados internacionales, Ginebra, 8 de junio de 1977 (PA I).

36 Protocolo II adicional a los Convenios de Ginebra de 1949 relativo a la protección de las víctimas de los conflictos armados sin carácter internacional, Ginebra, 8 de junio de 1977 (PA II).

37 En el DIH positivo, ver, Declaración de San Petersburgo de 1868 con el objeto de prohibir el uso de determinados proyectiles en tiempo de guerra, San Petersburgo, 11 de diciembre de 1868, preámbulo; Convención relativa a las leyes y costumbres de la guerra terrestre y su Anexo, La Haya, 1907, preámbulo, párr. $5^{\circ}$ y párr. $8^{\circ}$ que establece la "Cláusula Martens"; Protocolo Adicional I de 1977, Ginebra, 1977, art. 1(2).

Número de página no utilizable para citar 
recíprocamente. Así, para Schmitt, los objetivos estatales que influyen en la creación del DIH serían dos. En primer lugar, estaría la "habilidad de perseguir y resguardar intereses nacionales vitales", motivo por el cual los Estados evitan que las reglas del DIH restrinjan indebidamente su libertad de acción en el campo de batalla, perjudicando este interés. El principio de necesidad militar es el mecanismo del DIH para asegurar este propósito ${ }^{38}$. Un segundo objetivo estatal sería la obligación de "garantizar el bienestar de sus ciudadanos, proveyendo bienes comunes", como la seguridad e integridad física de la población. El principio de humanidad, que opera para proteger a la población -combatientes y no combatientes- y su propiedad, es la herramienta del DIH en ese sentido (Schmitt, 2010: 798-799). Es a la luz de ambos intereses -a veces alineados, a veces contrapuestos- que los Estados dan forma al DIH positivo.

Hay que reconocer, eso sí, que la necesidad militar no goza de buena fama en el derecho internacional. Una interpretación bastante difundida en el medio germánico, previo a las guerras mundiales, sostenía que la necesidad militar podía justificar las contravenciones al DIH, doctrina conocida como Kriegsraison geht vor Kriegsmanier ("la necesidad en la guerra prevalece sobre los modos de hacer la guerra"). Sin embargo, la Kriegsraison nunca tuvo real influencia en el DIH y fue tajantemente rechazada por el TMI de Núremberg ${ }^{39}$. Aun así, aquella falsa versión del principio de necesidad militar se ha prestado para la incomprensión del verdadero sentido del 'delicado balance' que permea transversalmente el DIH. Ello ha influido también en el sentido y alcance que pueda darse al principio de distinción.

En realidad, para Hayashi la necesidad militar refleja un criterio eminentemente pragmático de maximización de los recursos en el campo de batalla con vistas a la finalidad estratégica perseguida. Es un principio normativamente neutral o indiferente, en el sentido de dar libertad de acción a los Estados ${ }^{40}$. Por eso, la necesidad militar se manifiesta a través del DIH positivo como una cláusula de excepción prevista en la lex scripta que autoriza afectar bienes o personas protegidas, pero cuya invocación para desviarse de la regla general está sujeta a un control de razonabilidad según las circunstancias dadas ${ }^{41}$. En suma, y considerando que la necesidad militar ha sido prevista por los Estados al momento de crear el DIH positivo, ésta no puede ser invocada de novo para subsanar una conducta ilícita (Kriegsraison); pero tampoco permitiría tachar de ilícito aquellas conductas que parecen innecesarias, pero que no están prohibidas por el DIH (lo que Hayashi denomina contra-Kriegsraison) (Hayashi, 2016: 90-103).

38 Michael N. Schmitt, op. cit., p. 799.

39 TMI de Núremberg, EE.UU. v List (Caso de los Rehenes), Caso No 7, 19 de febrero de 1948, citado en Michael N. Schmitt, op. cit., p. 797.

40 P.ej., CG IV, art. 53, que prohíbe la destrucción de bienes en el territorio bajo ocupación "excepto en los casos en que tales destrucciones sean absolutamente necesarias a causa de las operaciones bélicas".

41 Hayashi propone que se debe ponderar los siguientes elementos: (a) cuál es la finalidad militar; (b) que el medio sea necesario, según circunstancias dadas; (c) que la finalidad respete el DIH; (d) y que el medio empleado no esté prohibido por el DIH. 
Por su lado, la 'humanidad' es un concepto difícil de definir, por su eminente contenido moral. En el contexto del DIH se ha declarado que la humanidad prohíbe infligir sufrimiento, heridas o destrucción innecesaria para alcanzar los legítimos fines militares; o que sería sinónimo de la prohibición de causar daño superfluo y sufrimiento innecesario; o como equivalente a la Cláusula Martens; o como el vehículo a través del cual los derechos humanos se introducen en la regulación de los conflictos armados. De cualquier modo, generalmente se utiliza en sentido descriptivo, tildando tal o cual acción como "humana" o "inhumana". Pero a diferencia de la necesidad militar, el principio de humanidad puede ser normativamente indiferente o no indiferente, dependiendo del asunto en cuestión (Hayashi, 2016: 93). Así, la humanidad puede llevar a que el DIH positivo disponga que ciertas conductas son imperativas ${ }^{42}$, prohibidas $^{43} \mathrm{O}$ permitidas $^{44}$. Por lo mismo, y aunque ya ha sido considerada por los Estados en la creación del DIH positivo, pareciera ser que nada impide invocar de novo la humanidad, ya sea para justificar una conducta que se desvía de las prescripciones del $\mathrm{DIH}^{45}$, como para rechazar un acto legal, aunque ello es más discutible para autores como Dinstein o Schmitt (Hayashi, 2016: 103-104).

Con todo, el equilibrio que se logre entre necesidad militar y humanidad viene siempre determinado por las circunstancias históricas, y si las circunstancias varían importantemente, los Estados podrían cuestionar el equilibrio imperante buscando su modificación (Schmitt, 2010: 799).

La marcada tendencia post-guerras mundiales ha sido privilegiar los aspectos humanitarios del $\mathrm{DIH}^{46}$. Esta predisposición también gatilló reformas en relación con el principio de distinción entre combatientes y civiles. Así, el debate más acalorado se ha centrado en torno a la idea de conferirle el estatus de combatientes a ciertos grupos que tradicionalmente el derecho internacional deja fuera de aquella categoría. Nos referimos derechamente a miembros de grupos armados organizados no estatales que pelean contra las fuerzas estatales - v.gr. rebeldes, guerrillas, fuerzas paramilitares, grupos terroristas, etc.- denominados a veces como luchadores (fighters), precisamente, para diferenciarlos de los combatientes regulares.

42 P.ej., manda adoptar riesgos en favor de los civiles; el cuidado de los heridos y enfermos; etc.

43 P.ej., prohíbe atacar directamente a la población civil; prohíbe el saqueo, la tortura; etc.

44 P.ej., permite la censura de comunicaciones de los prisioneros de guerra con el exterior; reconocer ciertas zonas para hospitales; etc.

45 Hayashi pone el ejemplo del art. 118 del CG III, que obliga a los Estados a repatriar a los prisioneros de guerra inmediatamente producido el cese de las hostilidades. Sin embargo, en diferentes conflictos (p.ej. guerra de Corea, IranIraq, el Golfo, etc.) muchos prisioneros de guerra sencillamente no querían ser repatriados a sus Estados. El incumplimiento de aquella obligación de repatriar, por motivos de "humanidad", debiera estar justificado según las circunstancias dadas.

46 Nótese el cambio de terminología para referirse al corpus del ius in bello, desde el "Derecho de la Guerra" del período de La Haya, pasando por el leguaje del "Derecho de los Conflictos Armados" de los Convenios de Ginebra de 1949, hasta el reconocimiento de la actual nomenclatura de "Derecho Internacional Humanitario".

Número de página no utilizable para citar 
Por ejemplo, los artículos 1(4) y 44(3) del Protocolo Adicional I de 1977 establecen dos excepciones a la regla tradicional. La primera disposición prescribe que las "guerras de liberación nacional" constituyen conflictos armados internacionales, motivo por el cual, los rebeldes que pelean contra el Estado podrían llegar a ser considerados combatientes, pero ello solamente si cumplen los requisitos del artículo $1^{\circ}$ de la RH IV. La segunda norma, por su parte, dispone que los partisanos o guerrilleros que no se distinguen de la población civil (p.ej. porque no usan uniformes), pueden conservar su estatus de combatiente si llevan sus armas abiertamente mientras sea visible al enemigo ${ }^{47}$. Sin embargo, para algunos Estados tales reglas destruyen el 'delicado balance' entre necesidad militar y humanidad (Schmitt, 2010: 812). Quizás por ello, el Protocolo Adicional I de 1977 no ha tenido la popularidad esperable entre los Estados, alcanzando solamente 174 ratificaciones como tratado ${ }^{48}$.

Más radical todavía es la idea de conferirle "derechos" a los luchadores en conflictos armados no internacionales. Si tradicionalmente el derecho internacional ha considerado que estos grupos no son más que "bandas irregulares" de hombres peleando, que por definición cometen actos ilegales -delictuales- según el derecho doméstico, no han faltado propuestas para que el DIH les confiera parte de los privilegios de los combatientes (p.ej. estatus de PdG), con la finalidad, se dice, de proteger a estos grupos e incentivarlos en el cumplimiento de las reglas y leyes básicas de la guerras (Cassese, 2012: 519-524). A la fecha, sin embargo, todos los intentos por reformar el DIH vigente en esa dirección, han fracasado. Los luchadores no son una categoría vigente en el derecho internacional. Aunque esté reconocido que éstos participan de las hostilidades en los hechos, lo hacen sin derecho: su participación en las hostilidades es antijurídica frente al derecho internacional; lo anterior, sin desconocer una mínima protección de sus derechos esenciales ${ }^{49}$.

\subsection{Fundamentos éticos del principio de distinción}

La justicia de la guerra es un tema recurrente en la filosofía moral. Habiendo examinado ya los fundamentos históricos y políticos del principio de distinción, en este apartado intentaremos explicar: primero, cuál sería el fundamento ético de la distinción entre combatientes y población civil; y segundo, qué es lo que autoriza moralmente a los combatientes a atacarse entre sí durante el conflicto armado.

47 Con todo, la interpretación de esta norma se discute.

48 Incluyendo Palestina. En cambio, no son Estados Partes del PA I potencias militares relevantes como Estados Unidos, Rusia, Israel, Paquistán, India, Irán, entre otras. Fuente: https://ihl-

databases.icrc.org/applic/ihl/ihl.nsf/States.xsp?xp_viewStates=XPages_NORMStatesParties\&xp_treatySelected $=470$ [revisado en septiembre 2019]

49 El DIH solamente les garantiza un mínimo de protección, ver, art. 3 común a los cuatro CGs.

Número de página no utilizable para citar 
Aparentemente, la exigencia de distinguir entre combatientes y civiles está conectada con nociones universales de lo que se considera moralmente correcto o incorrecto dentro de los conflictos armados. La tendencia histórica -como vimos- ha sido excluir del alcance de las hostilidades a cierta 'clase de personas', de tal modo que matar o herir a esas personas deja de ser un acto de combate legítimo y pasa a constituir un acto ilegítimo, incluso un crimen de guerra. Ello demuestra que existiría una concepción universal de que el conflicto armado es un combate entre combatientes (Walzer, 1977: 42). Pero aunque se trata de un sentimiento moral innegable, la justificación en este punto no es pacífica, ya que dependiendo del punto de inicio del argumento, se llega a conclusiones diversas.

Para Walzer, los soldados -que portan armas efectivamente- constituyen un peligro hacia el bando enemigo, y por eso, pierden de algún modo su derecho a la vida y a la libertad por la que pelean en nombre del Estado, y a cambio, ganan otros derechos propios de la guerra (war rights) como combatientes y potenciales prisioneros; pero desde ese momento pueden ser atacados por los soldados enemigos, aunque no hayan cometido crimen alguno. En cambio, todas las demás personas conservan sus derechos y los Estados debieran seguir comprometidos en respetarlos y protegerlos (Walzer, 1977: 127-137) ${ }^{50}$. Esta explicación parecería justificar fácilmente la exigencia ética de excluir a la población civil de los males provocados por las hostilidades: niños, mujeres y ancianos no pueden considerarse seriamente un peligro para los beligerantes; luego, no existe justificación para matarlos o herirlos en combate.

La misma explicación permitiría justificar también el derecho que poseen los combatientes para atacarse entre sí. Walzer considera que existe una 'igualdad moral' de los combatientes. Independiente si el soldado pelea por una causa justa o injusta en sentido de ius ad bellum, los combatientes de ambos lados gozan de los mismos derechos, privilegios, inmunidades y obligaciones. A su juicio, solamente los combatientes efectivamente peleando pueden atacarse lícitamente entre sí, porque constituyen un peligro recíproco. En cambio, éstos recuperarían su derecho a la vida cuando no son una amenaza para sus enemigos. Métodos como la hostilidad permanente, francotiradores, ataques sorpresa, debieran ser proscritos por inmorales. La dificultad ha sido, sin embargo, que el reconocimiento internacional de esta 'igualdad moral' de los combatientes beneficiaría a las grandes potencias militares que cuentan con ejércitos capaces de salir victoriosos en un enfrentamiento abierto, por lo que han sido los Estados más pequeños quienes se oponen a fijar límites a la vulnerabilidad de los soldados enemigos con el fin de obtener algún tipo de ventaja militar -cuyo extremo es la estrategia de guerrillas-(Walzer 1977: 138-144) ${ }^{51}$.

50 Walzer explica: “'Los soldados están hechos para morir’, dijo alguna vez Napoleón; por eso la guerra es un infierno. Pero incluso si nos colocamos en el infierno, todavía podríamos afirmar que nadie más que los soldados está hecho para morir. Esa distinción es la base de las reglas de la guerra”, p. 136.

51 Walzer demuestra esta 'igualdad moral' en los reparos que causa entre los propios soldados la experiencia de verse ante la decisión de disparar a enemigos desnudos, tomando café o fumando un cigarro, entre otras circunstancias que no suponen un peligro para sus enemigos. Así también, p.ej. el Código Lieber establece una prohibición de disparar a centinelas.

Número de página no utilizable para citar 
Para Jeff McMahan, en cambio, esta es una falsa justificación moral pues se desentiende de las causas de la guerra, cuestión que determina necesariamente la posición moral de los beligerantes. Para un examen de la moralidad de las reglas de ius in bello, éstas no pueden ser independientes del ius ad bellum (McMahan 2004: 708-718). McMahan considera que Walzer hace una incorrecta aplicación de la doctrina de la legítima defensa ya que el ejercicio de la legítima defensa implica examinar la causa del acto defensivo, y es comúnmente aceptado que la respuesta frente a un ataque injusto no le confiere al atacante un supuesto derecho a repeler la acción defensiva de la víctima: ex injuria non oritur ius. Si no puede haber defensa lícita frente a un ataque justo, los combatientes del Estado agresor no tendrían un derecho moral a atacar matar, herir o capturar- a sus enemigos del Estado agredido. El problema, a juicio de McMahan, sería más bien epistemológico ya que en el orden internacional, al menos por ahora, no existe quién determine de manera oportuna, vinculante y definitivamente, si una guerra se basa en una causa justa o injusta. De hecho, generalmente, los soldados creen estar peleando con causa justa. La conclusión, para McMahan, es que solamente los combatientes del Estado agredido -que pelean una guerra defensiva- tienen un derecho moral para atacar a los combatientes del Estado agresor, lo cual habría sido reconocido por el derecho internacional vigente. En cambio, la autorización que se les da a los combatientes del Estado agresor para atacar a los combatientes del Estado agredido, es únicamente una creación del derecho internacional -como regla consuetudinaria y convencional-. La igualdad de los combatientes no tiene base ética, sino que, por razones pragmáticas, el DIH les confiere un permiso jurídico a los combatientes "injustos" para realizar ataques moralmente incorrectos (McMahan, 2007: 97-101). Para McMahan, en este punto el DIH positivo establecería una regla inmoral, pero aparentemente- conveniente en sentido práctico.

Estos asuntos habían sido respondidos siglos atrás por Francisco de Vitoria en su Relecciones sobre los Indios. Vitoria se preguntaba, por una parte, si los súbditos están obligados a examinar las causas de la guerra, a lo cual replicaba, que "si al súbdito le consta la injusticia [de la causa] de la guerra, no le es lícito ir a ella, aunque el príncipe se lo ordene" ya que en virtud de ninguna autoridad es lícito dar muerte a un inocente (párr. 22). En la lógica clásica, si el Estado agresor no tiene justa causa, entonces, los combatientes del Estado agredido serían inocentes, sin que exista ningún derecho moral de parte de los combatientes a matar, herir o capturar a sus enemigos inocentes ${ }^{52}$. Por cierto, esta confusión entre ius ad bellum e ius in bello del DIH clásico es una de las principales diferencias con el ius in bello moderno, construido sobre la base de la irrelevancia del ius ad bellum, haciendo el DIH igualmente aplicable para ambos Estados

52 Francisco de Vitoria va aún más lejos, afirmando que, si existen indicios y razones de la injusticia de la guerra, la ignorancia de los súbditos combatientes no sería excusa para participar en ella, op. cit. párr. 23-26, y agrega que quien duda de su derecho, pero es negligente en buscar la verdad, no actúa de buena fe, ídem., párr. 29-30; aunque reconoce que sería lícito para los súbditos participar de la guerra en caso de duda, si la duda persiste, ídem., párr. 31.

Número de página no utilizable para citar 
beligerantes, tanto agresor como agredido (O'Connell, 2013: 10-11) ${ }^{53}$. Respecto el fundamento de la distinción entre combatientes y civiles, por otra parte, para Vitoria existiría una presunción de inocencia en favor de los niños, mujeres, clérigos y religiosos, así como de los labradores inofensivos y la demás gente civil y pacífica, la cual persiste mientras no conste lo contrario, "como ocurriría si se les encontrara combatiendo" (párr. 36). Dicha presunción sería el fundamento de su protección por el ius in bello. Aquel principio moral ha sido también recogido en el DIH moderno que protege a los civiles en la medida que no participen directamente de las hostilidades ${ }^{54}$.

\section{Conclusiones}

El principio de distinción obliga a los Estados a distinguir entre civiles y combatientes en el contexto de los conflictos armados.

Una revisión histórica del DIH permite entender la evolución que ha tenido aquella obligación internacional. Ya en el DIH antiguo se reconoce la existencia de una casta o grupo de personas (combatientes) regidos por un estatuto jurídico diverso vis-a-vis la población civil. Esta idea normativa es transversal a diversas culturas y civilizaciones. El DIH moderno ha reconocido positivamente aquel principio jurídico, en tratados y costumbre.

Por otro lado, existe un trasfondo político que sustenta el principio de distinción. Como manifestación de este principio, los Estados han creado y reconocido reglas para satisfacer sus intereses en el plano internacional, con tal de tener cierto grado de libertad de acción en el campo de batalla (necesidad militar) y al mismo tiempo proteger la vida y propiedad de sus ciudadanos (humanidad). Este 'delicado balance' entre intereses militares y humanitarios de los Estados, cambia según las épocas, viviendo actualmente un proceso de humanización del DIH. Se debe tener a la vista este sensible equilibrio de intereses estatales si se quiere hacer del DIH un derecho eficaz.

Finalmente, existen fuertes argumentos morales para justificar el principio de distinción entre combatientes y civiles. Independiente del disenso en la fundamentación ética de esta obligación internacional, hay amplio consenso en considerar el principio de distinción como uno de los

\footnotetext{
53 Ello tiene consagración positiva en el Preámbulo del Protocolo Adicional I de 1977: "(...) las disposiciones de los Convenios de Ginebra del 12 de agosto de 1949 y del presente Protocolo deben aplicarse plenamente en toda circunstancia a todas las personas protegidas por esos instrumentos, sin distinción alguna de carácter desfavorable basada en la naturaleza o el origen del conflicto armado o en las causas invocadas por las Partes en conflicto o atribuidas a ellas".

54 PA I de 1977, artículo 51(3).
} 
pilares del DIH. Por lo mismo, un estudio del DIH no puede pasar por alto los argumentos morales de esta primordial obligación de los Estados.

\section{Referencias bibliográficas}

BuOnO-CuOre VAras, Raúl. "Los tratados en el mundo romano”, Revista de Estudios HistóricoJurídicos XXV (2003): 23-34

Cassese, Antonio. "Should Rebels be Treated as Criminals? Some Modest Proposals for Rendering Internal Armed Conflicts Less Inhumane", en Realizing Utopia: The Future of International Law (Nueva York: OUP, 2012), 519-524.

CORTE INTERNACIONAL DE JUSTICIA, Opinión consultiva sobre la Legalidad de la amenaza o el empleo de armas nucleares, 8 de julio de 1996, 215, párr. 76.

D'Ors, Álvaro. Una introducción al estudio del Derecho (Valparaíso: Ed. PUCV, $4^{\circ}$ edición, 2003), 119-120.

DinsTEIN, Yoram. "Unlawful Combatancy", en International Law and the War on Terror (International Law Studies V. 79), por Fred L. Borch y Paul S. Wilson (eds.), (Newport: US Naval War College, 2003), 151-174.

DrAPER, G.I.A.D. "Combatant status: An historical perspective”, Military Law \& Law of War Review, $\mathrm{N}^{\circ} 11$ (1972): 136-137.

FLECK, Dieter. “The law of non-international armed conflict", en The Handbook of International Humanitarian Law, por Dieter Fleck (ed.), (Oxford: OUP, 2013), 581- 608.

Gray, Colin S. War, Peace and International Relations (Abingdon-on-Thames: Routledge, 2007), 15-27; 31-48; 115-122; 124-141.

HAYASHI, Nobuo. "Basic principles", en Routledge Handbook on the Law of Armed Conflict, por Raiin Livoja y Tim McCormack (eds.), (Abingdon-on-Thames: Routledge, 2016), 89.

IPSEN, Knut. "Combatants and non-combatants", en The Handbook of International Humanitarian Law, por Dieter Fleck (ed.), (Oxford: OUP, 2013), 308-309.

KLEFFNER, Jann K. "Protection of the wounded, sick and shipwrecked", en The Handbook of International Humanitarian Law, por Dieter Fleck (ed.), (Oxford: OUP, 2013), 321-322.

Número de página no utilizable para citar 
Fundamentos del Principio de Distinción en el Derecho Internacional Humanitario Ruggero Cozzi Elzo

KrahenmanN, Sandra. "Protection of prisoners in armed conflict", en The Handbook of International Humanitarian Law, por Dieter Fleck (ed.), (Oxford: OUP, 2013), 359-412.

MCMAHAN, Jeff. "Ethics of Killing in War", Ethics, N 114 (2004): 708-718.

MCMAHAN, Jeff. "The sources and status of just war principles", Journal of Military Ethics, 6 (2) (2007): 97-101.

Moderne, Frank. Principios Generales del Derecho Público (Santiago: Ed. Jurídica de Chile, 2005), 36.

MÜNKLER, Herfried. "The wars of the 21st century", Revista Internacional de la Cruz Roja, 85 (849) (2003), 7-21.

O'CONNELL, Mary E. "Historical development and legal basis", en The Handbook of International Humanitarian Law, por Dieter Fleck (ed.), (Oxford: OUP, 2013), 15-20.

SCHMITT, Michael N. "Military necessity and humanity in international humanitarian law: preserving the delicate balance", Virginia Journal of International Law, 50(4) (2010), 798799 .

WALZER, Michael. Just and Unjust Wars (Nueva York: Basic Books, 5ta ed., 2015), 42; 127-144. 